
"48 Центральный научно-исследовательский институт» Министерства обороны Российской Федерации, 141306, Российская Федерация, г. Сергиев Посад, ул. Октябрьская, д. 11

\begin{abstract}
Поступила 16.04.2020 г. Принята к публикации 29.03.2020 г.
Генетическое разнообразие коронавирусов и их изменчивость обеспечиваются за счет высокой частоты рекомбинации их геномной РНК, что способствует спонтанному появлению вирусов с новыми свойствами, которые потенциально могут быть причиной возникновения вспышек особо опасных и экзотических инфекционных заболеваний. В декабре 2019 - январе 2020 гг. в КНР выявлено новое коронавирусное заболевание, впоследствии получившее название COVID-19 (англ. Corona Virus Disease 2019), вызываемое вирусом SARS-CoV-2. Цель работы - анализ возможного механизма возникновения вспышки COVID-19 и свойств этиологического агента заболевания, вируса SARS-CoV-2. Проведено сравнение зоонозного резервуара патогенных для человека коронавирусов, возбудителей тяжелого острого респираторного синдрома (SARS - англ. Severe Acute Respiratory Syndrome), Ближневосточного респираторного синдрома (MERS - англ. Middle East Respiratory Syndrome) и COVID-19, а также клинических признаков вызываемых ими заболеваний. Рассмотрен возможный механизм формирования эпидемических вспышек. Для COVID-19 представлены хронология возникновения вспышки (впоследствии переросшей в пандемию) с начала декабря 2019 г. по конец марта 2020 г., таксономические и молекулярно-биологические характеристики этиологического агента заболевания, вируса SARS-CoV-2, и его место на филогенетическом древе коронавирусов. Рассмотрены основные направления борьбы с распространением инфекции.
\end{abstract}

Ключевые слова: ближневосточный респираторный синдром (MERS); коронавирус SARSCoV-2; коронавирусы; новое коронавирусное заболевание (COVID-19); тяжелый острый респираторный синдром (SARS); эмерджентные вирусные инфекиии.

Библиографическое описание: Сизикова Т.Е., Карулина Н.В., Петров А.А., Лебедев В.Н., Борисевич С.В. Новая опасная эмерджентная коронавирусная инфекиия // Вестник войск РХБ защзиты. 2020. Т. 4. № 1. С. 21-31. https://doi.org/10.35825/2587-5728-2020-4-1-21-31

Эмерджентные инфекции (заболевания, представляющие угрозу для здравоохранения, вызванные ранее неизвестным возбудителем) на протяжении длительного времени представляли перманентную угрозу для людей. Основными причинами появления эмерджентных инфекций являются мутационная изменчивость микроорганизмов, расширение ареала хозяйственной деятельности человека, развитие пассажирских и грузовых перевозок, приведшее к резкому повышение контактов человека с природой.

Возбудители эмерджентных вирусных инфекций относятся к различным таксономическим группам вирусов. Среди опасных и особо опасных эмерджентных вирусных инфекций начала XXI века видное место занимают заболевания, этиологическими агентами которых являются коронавирусы. Это тяжелый острый респираторный синдром (SARS - англ. Severe Acute Respiratory Syndrome), Ближневосточный респираторный синдром (MERS - англ. Middle East Respiratory Syndrome) и выявленная в конце 2019 года новая коронавирусная пневмония (COVID-19), вызванная новым коронавирусом, получившим в середине февраля 2020 г. название вирус SARS-CoV-2 . Вспышка заболевания, вызванная данным возбудителем, впоследствии переросла в пандемию, объявленную ВОЗ 11 марта 2020 г. 
Цель работь - анализ возможного механизма возникновения вспышки COVID-19 и свойств этиологического агента заболевания, виpyca SARS-CoV-2.

Коронавирусы представляют собой оболочечные вирусы с одноцепочечной «плюс» РНК, с размерами генома от 25 до 32 тысяч нуклеотидных остатков (н.о.) (самые большие из известных геномов среди РНК-содержащих вирусов), которые вызывают респираторные и кишечные заболевания животных и человека $[1,2]$.

Коронавирусы образуют подсемейство Orthocoronavirinae в пределах семейства Coronaviridae, порядка Nidovirales. Coгласно классификации Международного комитета по таксономии вирусов (ICTV), в настоящее время семейство Coronaviridae включает 4 рода: Alphacoronavirus, Betacoronavirus, Gammacoronavirus и Deltacoronavirus. Коронавирусы распределены на роды на основе определения степени гомологии семи высококонсервативных доменов репликазного полипротеина [1]. Заболевания человека вызывают представители родов Alphacoronavirus и Betacoronavirus. Генетическое разнообразие коронавирусов и их изменчивость обеспечиваются за счет высокой частоты рекомбинации их геномной РНК и способности геномов коронавирусов приобретать и утрачивать домены [1-4].

Именно эти факторы и способствуют спонтанному появлению коронавирусов с новыми свойствами, которые способны адаптироваться к новым хозяевам и экологическим нишам, что потенциально может быть причиной возникновения вспышек вызываемых ими заболеваний.

До 2002 года были известны только два патогенных для человека коронавируса, HCoV-OC43 и HCoV-229E (род Alphacoronavirus), которые вызывают инфекционный процесс верхних дыхательных путей у человека. Они считались одной из важных (около 15 \%) составных частей спектра патогенов, вызывающих респираторные заболевания.

В 2002 году зарегистрировано появление нового коронавируса (SARS-CoV), являющегося этиологическим агентом SARS. Циркуляция в течение 2002-2003 гг. данного возбудителя привела к более чем 8 тыс. случаев заболевания, клиническая картина которого характеризовалась первичной вирусной пневмонией с выраженным респираторным син- дромом. Летальность среди заболевших составляла около $10 \%$ [5].

Ретроспективный анализ установил, что SARS-CoV относительно недавно появился в человеческой популяции из зоонозного резервуара [5].

После пандемии ТОРС были идентифицированы еще два человеческих коронавируса, NL63 и HKU1, вызывающие заболевания верхних и нижних дыхательных путей человека. Филогенетический анализ выявил, что эти коронавирусы циркулировали в человеческой популяции длительное время.

25 сентября 2012 г. ВОЗ сообщила о выявлении нового коронавируса, возбудителя тяжелой респираторной инфекции, сопровождающейся лихорадкой, респираторными симптомами, носовыми кровотечениями, пневмонией. Случаи заболевания были ассоциированы с постоянным пребыванием или посещением стран Аравийского полуострова (Саудовская Аравия и Катар). Секвенирование полученного из проб пациента возбудителя ${ }^{1}$ в Медицинском Центре Эразма Роттердамского (ЕМС) в г. Роттердам (Нидерланды) позволило открыть новый коронавирус человека, впоследствии получивший название «коронавирус - возбудитель Ближневосточного респираторного синдрома (MERS-CoV) [6].

Установлены случаи MERS при отсутствии каких бы то ни было контактов с животными ${ }^{2}$, что указывает на возможность трансмиссии от человека к человеку $[7,8]$. Более того, вероятно, что инфекция от человека к человеку передается респираторным путем [9].

В 2013-2019 гг. случаи MERS, кроме стран, расположенных на Аравийском полуострове, были выявлены в Германии, Греции, Италии, Франции, Бельгии, Нидерландах, Люксембурге, Алжире, Египте, США, Австралии, Южной Корее, Китае. Все первичные случаи заболевания в том или ином регионе были так или иначе связаны с посещением стран Ближнего Востока ${ }^{2}$. Для эпидемиологической характеристики заболевания это имеет весьма важное значение, так как Саудовскую Аравию во время хаджа ежегодно посещают миллионы мусульман, проживающих во многих странах [10-13]. Если число случаев заболевания в европейских странах ${ }^{3}$ и США является ограниченным [11], то во время вспышки MERS в Южной Корее выявлено в общей сложности 169 лабораторно подтвержденных случаев заболевания [13].

\footnotetext{
1 Health Protection Agency. A Case of novel coronavirus identified in the UK. 11 February 2013. URL: http://www9. who.int/csr/don/2013_02_11b/en/ (дата обращения: 28.02.2020).

2 Novel coronavirus - Saudi Arabia. URL: https://promedmail.org/promed-post/?id=2390003 (дата обращения: 28.02.2020).

3 European Center for Disease Prevention and Control, Stockholm, 2018. Severe respiratory disease associated with MERS coronavirus (MERS-CoV). URL: https://www.ecdc.europa.eu/en/publications-data/rapid-risk-assessmentsevere-respiratory-disease-associated-middle-east-11 (дата обращения: 28.02.2020).
} 

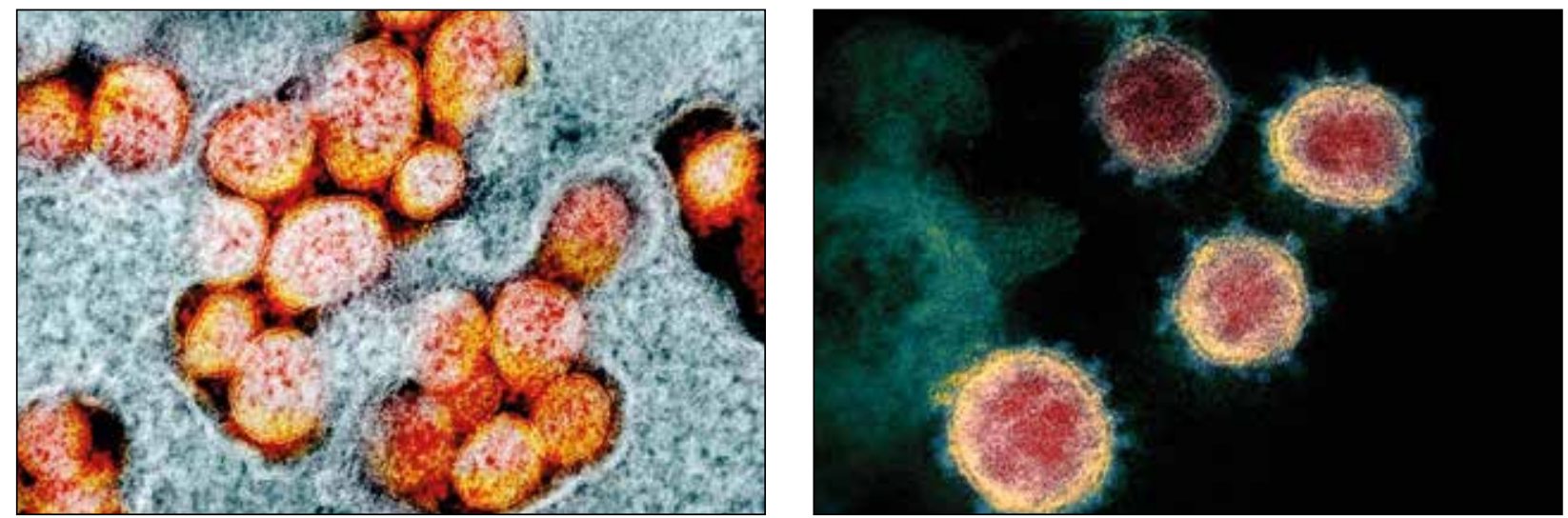

Рисунок 1 - Фотографии вирионов коронавируса, сделанные при электронной микроскопии инфицированной культуры клеток ${ }^{1,2}$

$\begin{array}{ll}1 & \text { URL: https://news.mail.ru/society/41028456/gallery/1028904/ (дата обращения: 28.02.2020). } \\ 2 \text { URL: https://news.mail.ru/society/41028456/gallery/1028906/ (дата обращения: 28.02.2020). }\end{array}$

Всего по состоянию на 3 февраля 2020 г. зарегистрировано 2499 лабораторно подтвержденных случаев заболеваний, вызванных вирусом MERS, из которых 861 завершились летальным исходом ${ }^{4}$.

Периодически возникающие случаи MERS вызывают тревогу органов здравоохранения в глобальном масштабе, поскольку они служат напоминанием о потенциальной угрозе коронавирусов для здравоохранения, отмеченной после вспышки SARS в 2003 году [10].

Следовательно, к концу 2019 года было выявлено шесть патогенных для человека коронавирусов, у каждого из которых установлена передача от человека к человеку.

1 декабря 2019 г. в г. Ухань (КНР) зарегистрирован первый случай пневмонии неясной этиологии, 31 декабря 2020 г. власти КНР известили ВОЗ о вспышке нового заболевания [14, 15]. Ухань - 7-й по численности город КНР, расположенный в центральной части страны примерно в 800 км к западу от Шанхая и 960 км к северу от Гонконга, его население составляет более 11 млн человек. Город является крупным транспортным логистическим узлом, через который проходят многие маршруты не только внутренних, но и международных пассажиропотоков.

Ухань имеет прямое воздушное сообщение с Москвой, Парижем, Лондоном, Римом. Туда ежегодно прилетают 6-65 тыс. граждан США, причем пик посещаемости приходится на январь (празднование Нового года по лунному кален- дарю). Ухань в ходе деловых и туристических поездок часто посещают граждане РФ.

Клинические признаки заболевания - новой коронавирусной пневмонии - лихорадка, в ряде случаев затрудненное дыхание, при рентгенографии грудной клетки интенсивные пневмонийные инфильтраты [14].

В соответствии с данными предварительных эпидемиологических исследований, большинство подтвержденных случаев заболевания зарегистрированы у рабочих Южно-китайского оптового рынка морепродуктов в Ухане и покупателей, часто посещающих данный рынок. С высокой долей вероятности установлено, что вспышка ассоциирована с рынком морепродуктов, на котором также продавали цыплят, кошек, фазанов, летучих мышей, сурков, ядовитых змей, тушки кроликов и различных диких животных. Указанный рынок морепродуктов был закрыт только 1 января 2020 г.

К началу 2020 г. поступила информация о 27 случаях заболевания. В КНР проведены исследования по идентификации этиологического агента заболевания ${ }^{5,6}$. На первом этапе были исключены такие респираторные патогены, как возбудители сезонного гриппа, гриппа A (H5N1), коронавирусы MERS-CoV и SARS-CoV, аденовирусы ${ }^{6}$ [16].

7 января поступило сообщение о том, что возбудителем пневмонии неизвестной этиологии в КНР является новый коронавирус. Вирусная РНК выделена от 15 больных, от 5 пациентов выделен биологически активный вирус.

\footnotetext{
4 World Health Organization. Middle East respiratory syndrome (MERS-CoV). URL: https:/www.who.int/ emergencies/mers-cov/en/ (дата обращения: 28.02.2020).

5 Novel Coronavirus - China. URL: https://www.who.int/csr/don/12-january-2020-novel-coronavirus-china/en/ (дата обращения: 28.02.2020).

6 Wuhan Health Commission: Pneumonia Cases Increase To 44, 11 Severe. URL: https://afludiary.blogspot. com/2020/01/wuhan-health-commission-pneumonia-cases.html (дата обращения: 28.02.2020).
} 


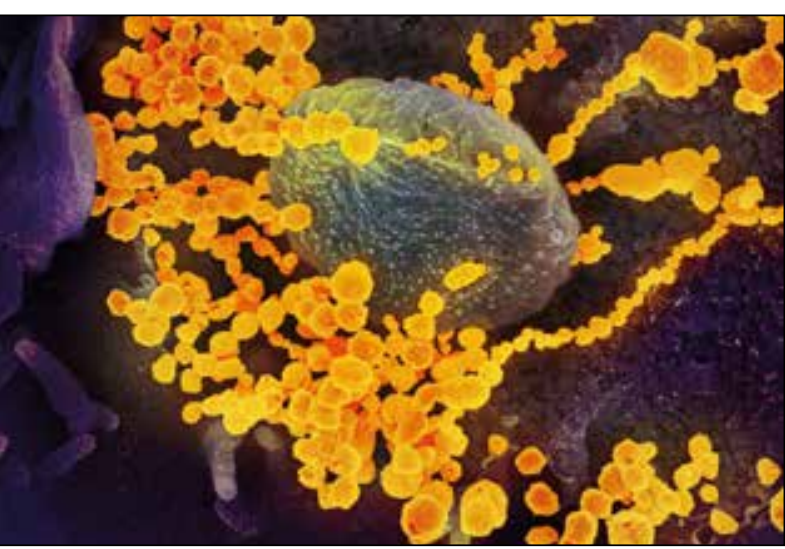

Рисунок 2 - Выход вирионов коронавирусов из инфицированных клеток ${ }^{1}$

\footnotetext{
1 https://news.mail.ru/society/41028456/gallery/ 1028899/ (дата обращения: 20.02.2020).
}

При электронной микроскопии возбудителя, выделенного из клинических проб, установлена морфология, характерная для коронавирусов

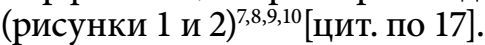

Проведено частичное, а затем и полногеномное секвенирование геномной РНК нового коронавируса [18], сначала получившего предварительное название $2019-\mathrm{nCoV}^{7}$, а 12 февраля 2020 г. ВОЗ утвердила название возбудителя как вирус SARS-CoV-2 ${ }^{11}$ [15]. Размер генома составил 29903 н.о. Структура генома сходна с таковой для других коронавирусов: 5'-нетранслируемый регион (№ позиций генома 1-265), гены репликазного комплекса (открытые рамки считывания OFR-1A, № позиций генома 266-13468) и OFR-1B (1346821555), ген S (21563-25384), ген OFR-3A (2539326220), ген E (26245-26472), ген M (26523-27191), ген OFR-6 (27202-27387), ген OFR-7 (2739427759), ген OFR-8 (27894-28259), ген N (2827429533), ген OFR-10 (29556-29674), 3/ -нетранслируемый регион (29675-29903) [15, 18].

Последовательность геномной РНК вируса SARS-CoV-2 сходна с таковой для коронавирусов, выделенных от летучих мышей (уровень гомологии более $90 \%$ ), но отличается от MERS-CoV и SARS-CoV (рисунок 3). Уровень гомологии с SARS-CoV не более $80 \%{ }^{7}$.

Генетический анализ 103 проанализированных изолятов вируса SARS-CoV-2 позволил выявить две линии, более вирулентную для че- ловека линию L и менее вирулентную линию $\mathrm{S}$. Линия S является предком линии L. Полногеномное секвенирование показало, что геномы данных линий различаются заменами в позициях 8782 (ген OFR-1A) и 28144 (ген OFR-8). Замена в позиции 8782 (линия S-T, линия L-C) является синонимической. Замена в позиции 28144 (линия $\mathrm{S}-\mathrm{C}$, линия L-T) приводит к замене серина (для линии S) в позиции 84 аминокислотной последовательности белка, кодируемого геном OFR-8 на лейцин (для линии L) [19].

Примерно до 19 января 2020 г. возможность трансмиссии возбудителя заболевания от человека к человеку оставалась неустановленной. Во всяком случае, власти КНР заявляли, что среди 763 лиц, тесно контактировавших с заболевшими, в том числе и 419 медицинских работников, новых случаев заболевания зарегистрировано не было [15]. Отсутствие на тот момент случаев заболевания среди медицинских работников следует особо подчеркнуть. Это можно объяснить либо тем, что уровень возможной трансмиссии возбудителя от больного человека здоровому на первом этапе вспышки являлся весьма ограниченным, либо тем, что медицинские службы КНР учли опыт вспышки SARS 2003 года и заранее предприняли необходимые меры предосторожности.

Полученные в результате секвенирования данные послужили основой для разработки наборов реагентов для выявления и идентификации возбудителя нового коронавирусного заболевания во многих странах, в том числе и в России ${ }^{8}$.

На основании полученной информации, ВО3 опубликовала протокол для диагностического тестирования заболевания, вызванного вирусом SARS-CoV-2, разработанный группой вирусологов госпиталя Charite [20], в котором было предложено для проведения диагностики в качестве клинических проб использовать носоглоточные смывы и сыворотки крови, взятые в острый период заболевания и у реконвалесцентов ${ }^{8}$.

Специалисты по материалам вспышки COVID-19 посчитали возможным провести разделение эпидемического процесса на три этапа. Первый этап вспышки характеризовался примерно одинаковым количеством зарегистрированных случаев заболевания, малым числом случаев заболевания за пределами г. Ухань, отсутствием убедительных свидетельств трансмиссии вируса от человека к человеку. Основанием

\footnotetext{
7 CDC Novel coronavirus, (2019-nCoV) Wuhan, China. URL: https://www.cdc.gov/ coronavirus/2019-nCoV/ summary.html (дата обращения: 28.02.2020).

8 URL: https://news.mail.ru/society/41028456/gallery/1028904/ (дата обращения: 28.02.2020).

9 URL: https://news.mail.ru/society/41028456/gallery/1028906/ (дата обращения: 28.02.2020).

${ }^{10}$ URL: https://news.mail.ru/society/41028456/gallery/1028899/ (дата обращения: 20.02.2020).

${ }^{11}$ Laboratory testing for 2019 novel coronavirus (2019-nCoV) WHO Interim guidance 14 January 2020. URL: https:// regnum ru/news/ society/2832232 (дата обращения: 28.02.2020).
} 


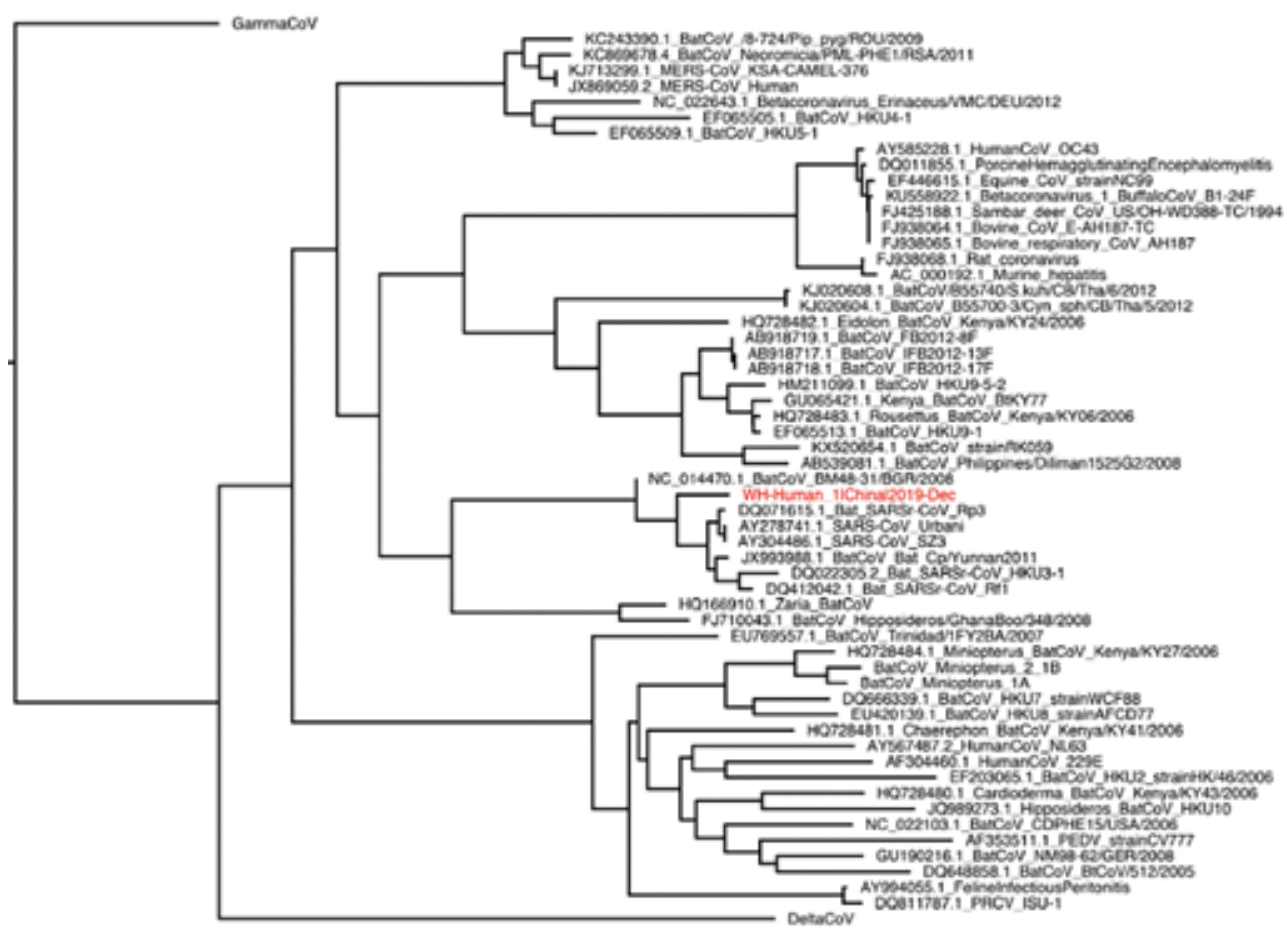

для заниженного уровня оценки опасности на первом этапе вспышки было, помимо отсутствия вторичных случаев заболевания, сопоставление доли тяжелых случаев заболевания (около $10 \%$ ) и летальных исходов (около 4 \%) по сравнению с показателями для SARS (уровень летальности $10 \%$ ) и MERS (уровень летальности 35 \%). Однако эпидемиологов насторожил тот факт, что при относительно низком числе заболевших уже были зарегистрированы случаи распространения заболевания за пределы КНР. Согласно проведенной эпидемиологической оценке, с учетом трансмиссии возбудителя заболевания за пределы КНР, истинное количество заболеваний должно быть существенно больше (оцениваемое значение показателя на тот момент - 1723 случая, при доверительном интервале с уровнем вероятности $95 \%$ от 427 до 4471 случаев) ${ }^{12}$ [21].

Хронология первого этапа вспышки заболевания, вызванного вирусом SARS-CoV-2 (с 12 декабря 2019 г. по 20 января 2020 г.), представлена в таблице 1.

Опасения эпидемиологов полностью подтвердились после 20 января 2020 г., когда произошел качественный скачок по оценке эпидемической опасности заболевания (второй этап вспышки). В этот день власти КНР заявили об уже 217 подтвержденных случаях заболевания, причем среди новых заболевших было 14 медицинских работников. Это косвенно подтвердило тот факт, что коронавирус SARS-CoV-2, как и другие патогенные для человека коронавирусы, может передаваться от человека к человеку.

После 20 января информация о новых случаях заболевания продолжает лавинообразно нарастать. Уже 24 января число заболевших (850 человек) вошло в указанный ниже доверительный интервал 9 . Установлено, что инкубационный период заболевания составляет от 2 до 14 суток (в среднем 5-6 суток) ${ }^{10}$.

Динамика роста числа выявленных случаев заболевания в период с 21 января по 13 февраля 2020 г. представлена в таблице 2. Для обработки поступающих данных был проведен расчет ежедневного коэффициента роста интегральной величины выявленных случаев заболевания (DI) по формуле (1):

$$
\mathrm{DI}=\mathrm{N}_{\mathrm{i}-} / \mathrm{N}_{\mathrm{i}-1}
$$

где: $\mathrm{N}_{\mathrm{i}-}$ - интегральная величина количества выявленных случаев заболевания на данный день;

$\mathrm{N}_{\mathrm{i}-1}$ - интегральная величина количества выявленных случаев заболевания на предшествующий день.

\footnotetext{
$\overline{12}$ China reports 136 more cases in two days (in Chinese). Wuhan Municipal Health Commission. 20 January 2020. URL: https://www.rt.com/news/478669-coronavirus-outbreak-china-wuhan-soars/ (дата обращения: 15.02.2020).
} 
Таблица 1 - Хронология вспышки заболевания, вызванного вирусом SARS-CoV-2, за период с 12 декабря 2019 г. по 20 января 2020 2.

\begin{tabular}{|c|c|c|}
\hline Дата & Событие & Источник \\
\hline 12.12.2019 & $\begin{array}{c}\text { Появление первого случая заболевания } \\
\text { (по данным ретроспективной диагностики) }\end{array}$ & 14,15 \\
\hline 31.12 .2019 & $\begin{array}{c}\text { Зарегистрировано } 27 \text { случаев заболевания, } \\
\text { о вспьшке информирована ВОЗ }\end{array}$ & $22,23,{ }^{13}$ \\
\hline 01.01 .2020 & Рынок морепродуктов в г. Ухань закрыт & 10 \\
\hline 05.01 .2020 & $\begin{array}{c}\text { Общее количество случаев заболевания достигло } 59 \text { человек. } \\
\text { Под наблюдением - } 163 \text { человека. В качестве возможных } \\
\text { этиологических агентов рассмотрены возбудители MERS, SARS, } \\
\text { сезонного гриппа, гриппа A (H5N1) }\end{array}$ & 14,15 \\
\hline 07.01 .2020 & Установлен этиологический агент заболевания - новый коронавирус & 16 \\
\hline 09.01 .2020 & Зарегистрирована первая гибель человека от заболевания & 22 \\
\hline 13.01 .2020 & Первый случай заболевания за пределами КНР (Таиланд) & 17 \\
\hline 15.01 .2020 & $\begin{array}{c}\text { ВОЗ рекомендован протокол для проведения лабораторной } \\
\text { диагностики }\end{array}$ & 20 \\
\hline 20.01 .2020 & $\begin{array}{c}\text { Заболевание отмечено у } 14 \text { медицинских работников, } \\
\text { контактировавших с больными (подтверждение возможности } \\
\text { передачи заболевания от человека к человеку) }\end{array}$ & 21 \\
\hline
\end{tabular}

Как следует из данных, представленных в таблице 2, число выявленных случаев заболевания на і-е сутки, в подавляющем большинстве случаев попадает в рамки доверительного интервала, рассчитанного по состоянию на (i-1) сутки. Показатель DI позволяет отслеживать динамику развития эпидемической вспышки. При устойчивом снижении данного показателя в течение 4 и более суток можно приблизительно определить возможное время ликвидации вспышки (значение DI - 1,00).

Для расчета можно использовать эмпирически установленную формулу (2):

$$
\mathrm{DI}_{(\mathrm{i})}=1+\left(\mathrm{DI}{ }_{(1)}-1\right) / \sqrt{ } \mathrm{I} \text {, }
$$

где DI (1) и DI (i) - значения показателя DI на первые и і-е сутки соответственно.

При использовании этой формулы, при задавании фиксированных значений показателя DI (i), можно ориентировочно рассчитать время достижения данного показателя по формуле (3):

$$
\mathrm{i}=\left[\left(\mathrm{DI}_{(1)}-1\right) /\left(\mathrm{DI}_{(\mathrm{i})}-1\right)\right]^{2},
$$

При этом за первый день следует брать дату, после которой отчетливо выявлена тенденция к снижению показателя DI.

Расчет по данным изменения показателя DI за период с 28 января по 13 февраля позволяет высказать предположение, что ориентировочная дата завершения вспышки в КНР (после которой возможно появление лишь отдельных спорадических случаев заболевания) 28-29 марта 2020 г., сокращение указанного срока возможно за счет интенсификации проводимых противоэпидемических мероприятий. Отмена 25 марта 2020 г. карантина в эпицентре вспышки в КНР - провинции Хубэй, а также прозвучавшие 29 марта 2020 г. заявления властей КНР о завершении активной фазы вспышки COVID-19 в стране в целом подтверждают корректность использованной методики расчета (для эпицентра вспышки).

Однако к 13 февраля 2020 г. случаи заболевания, вызванного вирусом SARS-CoV-2, зарегистрированы, кроме материкового Китая (заболевание в КНР зарегистрировано во всех 33 административных районах, в том числе в грани-

\footnotetext{
${ }^{13}$ Undiagnosed pneumonia - China (HUBEI): wildlife sales, market closed, RFI. Pro-MED-mail. International Society for Infectious Diseases. URL: https://promedmail.org/?lang=soas (дата обращения: 18.01.2020).

${ }^{14}$ Mystery pneumonia virus probed in China. BBC News. 3 January 2020. URL: https://crystalsweb.com/news/world/ mystery-pneumonia-virus-probed-in-china// (дата обращения: 0.02.2020).

15 2019-20 outbreak of novel coronavirus (2019-nCoV). URL: https://org/wiki/2019-20_outbrreak_of novel coronavirus (2019-nCoV) (дата обращения: 15.02.2020).

${ }^{16}$ Outbreak of Pneumonia of Unknown Etiology (PUE) in Wuhan, China. Centers for Disease Control and Prevention. 8 January 2020. URL: https://emergency.cdc.gov/han/han00424.asp.

${ }^{17}$ Pneumonia of unknown cause - China. Disease outbreak news. World Health Organization. 5 January 2020. URL: https://www.who.int/csr/don/05-january-2020-pneumonia-of-unkown-cause-china/en/ (дата обращения: 10.02.2020).
} 
Таблица 2 - Динамика роста числа выявленных случаев заболевания, вызванного вирусом SARS-CoV-2, во время второго этапа вспышки

\begin{tabular}{|c|c|c|c|}
\hline Дата & $\mathrm{Ni}-$ & DI & $\begin{array}{l}\mathrm{Ni}(195, \text { прогнозная величина по данным на } \\
\text { (i-1) день) }\end{array}$ \\
\hline 21.01.2020 & 235 & - & - \\
\hline 22.01.2020 & 367 & 1,56 & - \\
\hline 23.01.2020 & 574 & 1,56 & $558-586$ \\
\hline 24.01.2020 & 895 & 1,56 & $873-917$ \\
\hline 25.01 .2020 & 1408 & 1,57 & $1370-1440$ \\
\hline 26.01.2020 & 2120 & 1,50 & $2155-2265$ \\
\hline 27.01.2020 & 2902 & 1,37 & 3001-3259 \\
\hline 28.01.2020 & 4633 & 1,60 & $3877-4075$ \\
\hline 29.01.2020 & 6196 & 1,34 & $7228-7598$ \\
\hline 30.01 .2020 & 8235 & 1,32 & $8095-8511$ \\
\hline 31.01 .2020 & 9939 & 1,21 & 10598-11142 \\
\hline 01.02 .2020 & 12038 & 1,21 & $11725-12337$ \\
\hline 02.02 .2020 & 14638 & 1,22 & $14202-14930$ \\
\hline 03.02 .2020 & 17486 & 1,19 & 17492-18304 \\
\hline 04.02 .2020 & 20630 & 1,18 & 20288-21328- \\
\hline 05.02 .2020 & 24582 & 1,19 & 23734-24491 \\
\hline 06.02 .2020 & 28634 & 1,17 & 28252-29984 \\
\hline 07.02 .2020 & 31538 & 1,10 & $32663--34339$ \\
\hline 08.02 .2020 & 34957 & 1,11 & $34001-35741$ \\
\hline 09.02.2020 & 37558 & 1,08 & $37779-39715$ \\
\hline 10.02 .2020 & 40554 & 1,08 & $39553-41581$ \\
\hline 11.02 .2020 & 43102 & 1,06 & $42703-44891$ \\
\hline 12.02 .2020 & 45171 & 1,05 & $44545-46830$ \\
\hline 13.02 .2020 & 48076 & 1,06 & $46283-48616$ \\
\hline \multicolumn{4}{|c|}{$\begin{array}{l}\text { Примечание. } \\
\text { Прогнозную интегральную величину числа выявленных случаев заболевания на і день рассчитывали, } \\
\text { исходя из величин Ni u DI на і-1 день. }\end{array}$} \\
\hline
\end{tabular}

чащих с РФ провинции Хэйлунцзян, Внутренней Монголии, Синьцзян-Уйгурском автономном округе и Гирине), еще в 26 странах (Таиланд, Гонконг, Австралия, Малайзия, Сингапур, Тайвань, Франция, Япония, Вьетнам, Макао, Южная Корея, Филиппины, Камбоджа, США, Канада, Непал, Объединенные Арабские Эмираты, Германия, Италия, Бельгия, Финляндия, Россия, Испания, Швеция, Великобритания, Шри Ланка).

ВОЗ предупредила о возможности возникновения новых заболеваний, вызванных вирусом, в других странах. К сожалению, данный прогноз полностью оправдался.

С конца февраля 2020 г. можно говорить о третьем этапе вспышки COVID-19. Данный период характеризуется тем, что количество новых случаев заболевания, зарегистрированных за пределами КНР, выше, чем аналогичный показатель КНР. Быстрое распространение заболевания привело к тому, что 11марта 2020 г. ВОЗ объявила о пандемии COVID-19. На 2 апреля 2020 г. общее количество подтвержденных случаев COVID-19 составило 950063. При этом в перечне стран с наибольшим уровнем заболеваемости КНР (примерно 81 тыс. подтвержденных случаев) уже занимает только четвертое место после США (более 200 тыс. случаев), Италии и Испании (более 100 тыс. случаев). Общее количество летальных исходов при COVID-19 на 2 апреля 2020 г. достигло 48259 (19 \% от завершившихся либо выздоровлением, либо смертью больного случаев).

Не исключена возможность, что переход эпидемической опасности COVID-19 на более высокий качественный уровень связан с эволюци- 


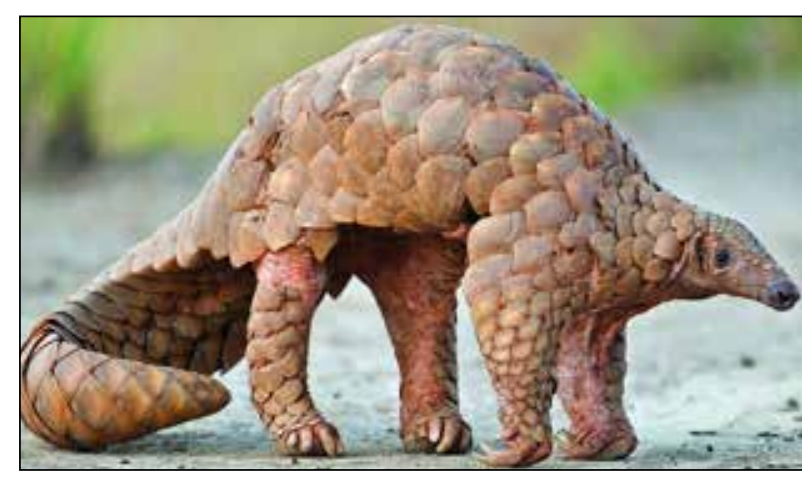

Рисунок 4 - Китайский панголин (Manis pentadactyla) - вероятный промежуточный хозяин вируса SARS-COV-2 $2^{12}$

\begin{abstract}
1 https://avatars.mds.yandex.net/get-pdb/ 1648714/366002d5-dba0-4656-bde5-d48295bb04ef/ s1200?webp=false (дата обращения: 10.02.2020).

2 Выявлен вероятный промежуточный хозяин вируca COVID-2019. Электронный ресурc: https://m.vz. Ru/ news/ 2020 (дата обращения: 10.02.2020).
\end{abstract}

онными изменениями генома возбудителя в ходе пассажа через человека (появление линии $\mathrm{L}$ виpyca SARS-CoV-2). Однако поскольку у изолятов вируса SARS-CoV-2, выделенных от больных с заболеванием различной степени тяжести, проходивших лечение в одном и том же медицинском учреждении, могут отсутствовать значимые генетические различия, можно сделать вывод, что основным фактором, определяющим тяжесть заболевания человека, является его физическое состояние и, возможно, иммунный статус.

При анализе свойств новых коронавирусов - возбудителей опасных и особо опасных эмерджентных вирусных инфекций XXI века, можно сделать вывод, что зоонозная трансмиссия коронавирусов животных могла стать причиной новых опасных инфекционных заболеваний человека. При этом необходимо рассмотреть при- родный резервуар возбудителей. Для вирусов MERS-CoV, SARS-CoV и, по косвенным данным, вируса SARS-CoV-2 - это рукокрылые [16, 24]. В качестве промежуточного хозяина для SARS-CoV были идентифицированы кошки циветты [25], для MERS-CoV - верблюды-дромадеры [7]. Для вируса SARS-CoV-2 промежуточным хозяином, предположительно, являются панголины из отряда плацентарных млекопитающих, близкие к броненосцам и муравьедам Геномная последовательность коронавируса панголинов на $99 \%$ идентична последовательности генома коронавируса человека SARS-CoV-2 (рисунок 4$)^{18,19}$.

Для всех рассмотренных коронавирусов возбудителей опасных эмерджентных заболеваний - может быть предложена одна и та же модель формирования вспышки (таблица 3).

При анализе схемы формирования вспышек опасных коронавирусных заболеваний следует обратить внимание на такой компонент вспышки, как промежуточный хозяин. Выявление в качестве такового кошек циветты при вспышке SARS в 2003 году внесло значительный вклад в борьбу с распространением инфекции. Контакты человека с промежуточным резервуаром MERS - верблюдами дромадерами в странах Аравийского полуострова являются обыденным явлением, но имеющаяся информация о данных животных, как составляющих компонентах эпидочага, по крайней мере, позволяет определить возможные группы риска.

Важная отличительная характеристика COVID-19 по сравнению с SARS и, особенно, MERS - в ходе развития вспышки заболевание преимущественно переходит в типичный антропоноз (человек является и резервуаром возбудителя, и вектором передачи, и восприимчивым объектом).

Для оценки опасности заболеваний, вызываемых новыми коронавирусами, необходимо

Таблица 3 - Схема возникновения вспышек заболевания, вызываемых вирусами MERS-CoV, SARS-CoV u SARS-CoV-2 [7, 25]

\begin{tabular}{|c|c|c|c|}
\hline \multirow{2}{*}{$\begin{array}{c}\text { Составляющий компонент } \\
\text { вспышки }\end{array}$} & \multicolumn{2}{|c|}{ Характеристика компонента для } \\
\cline { 2 - 4 } & MERS & SARS & Сукокрылые \\
\hline Природный резервуар возбудителя & \multicolumn{2}{|c|}{ Сошки циветты } & $\begin{array}{c}\text { Предположительно } \\
\text { панголины? }\end{array}$ \\
\hline Промежуточный хозяин & Верблюды дромадеры & Кошкиные \\
\hline Восприимчивый коллектив & $\begin{array}{c}\text { Первичные случаи заболевания человека (от промежуточного хозяина). Вторичные } \\
\text { случаи заболевания - заражение от больных с клиническими признаками заболевания, } \\
\text { возможно, и от носителей вируса с отсутствием симптомов заболевания }\end{array}$ \\
\hline
\end{tabular}

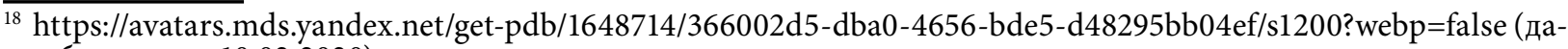
та обращения: 10.02.2020).

${ }^{19}$ Выявлен вероятный промежуточный хозяин вируса COVID-2019. Электронный pecypc: https://m.vz. Ru/ news/ 2020 (дата обращения: 10.02.2020).
} 
оценить потенциальные видовые барьеры. Эпителий дыхательных путей человека представляет собой входные ворота и первичную мишень для респираторных вирусов, в том числе и для патогенных для человека коронавирусов. При этом рецепторы для каждого отдельного вируса могут быть различными ${ }^{20}$.

Идентификация хозяйского клеточного рецептора, используемого каждым конкретным коронавирусом, поможет обеспечить понимание патогенеза легочного и почечного заболевания, а также позволит предложить эффективные способы лечения. Для вируса SARS-CoV-2 установлено, что рецептор-связывающий S-белок имеет высокую аффинность к ангеотензин-превращающему ферменту 2 (АПФ2) человека и так же, как и SARS-CoV, может использовать его для входа в чувствительные клетки.

Если к настоящему времени уже разработаны средства выявления и идентификации вируса SARS-CoV-2, то разработка средств специфической профилактики и лечения еще, по сути дела, находится на начальном этапе. По оптимистическим прогнозам, вакцина против COVID-19 может быть готова для применения только в конце 2020 года. Поэтому основным инструментом борьбы с пандемией COVID-19 сейчас являются санитарно-эпидемические мероприятия, в частности, введение режима карантина и самоизоляции.

\section{Выводы}

1. Новая коронавирусная инфекция (COVID19) заняла ведущее место в группе опасных эмерджентных вирусных инфекций XXI века.

2. Для всех рассмотренных коронавирусных инфекций характерен общий механизм формирования эпидемических вспышек. Причиной COVID19, как и других эмерджентных коронавирусных заболеваний человека (SARS и MERS), могла стать зоонозная трансмиссия коронавирусов животных.

3. Развитие транспортного и пассажирского потоков обеспечивает быстрое проникновение возбудителей в неэндемичные регионы с последующим формированием вспышек коронавирусных инфекций и перерастанием их в пандемию.

4. Для понимания эпидемиологии заболевания, вызванного вирусом SARS-CoV-2, требуется постоянный мониторинг поступающей информации, в частности, сведений по выявлению естественного хозяина (природного резервуара) возбудителя, любых возможных промежуточных хозяев, установлению способа инфицирования при первичных (от зоонозного резервуара) и вторичных (при передаче от человека к человеку) случаях заболевания.

\footnotetext{
${ }^{20}$ WHO. Epidemiological update: additional confirmed cases of novel coronavirus including sixth case diagnosed in Europe. URL: https://www.who.int/docs/default-source/coronaviruse/situation-reports/20200126-sitrep-6-2019-ncov.pdf (дата обращения: 28.02.2020).
}

\section{Информация о конфликте интересов}

Авторы заявляют, что исследования проводились при отсутствии любых коммерческих или финансовых отношений, которые могли бы быть истолкованы как потенциальный конфликт интересов.

\section{Сведения о реиензировании}

Статья прошла открытое рецензирование двумя рецензентами, специалистами в данной области. Рецензии находятся в редакции журнала.

\section{Список источников}

1. De Groot R.J. Family Coronaviridae // Virus taxonomy, the 9 th report of the international committee on taxonomy of viruses / Ed. King AMQ, Adams M.J., Cartens E.B., Lefkowitz E.J. San Diego: Academic Press, 2012. P. 806-828.

2. Gorbalenya A.E., Enjuanes L., Ziebuhr J., Snijder E.J. Nidovirales: evolving the largest RNA virus genome // Virus Res. 2006. V. 117. P. 17-37. https://doi.org/10.1016/j. virusres.2006.01.017

3. Masters P.S. The molecular biology of coronaviruses // Adv. Virus Res. 2006. V. 66. P. 193-292. https://doi.org/10.1016/S0065-3527(06)66005-3

4. Snijder E.J., Bredenbeek P.J., Dobbe J.C. et al. Unique and conserved features of genome and proteome of SARS-coronavirus, an early split-off from the coronavirus group 2 lineage // J. Mol. Biol. 2003. V. 331. P. 991-1004. https://doi.org/10.1016/s0022-2836(03)00865-

5. Peiris J.S., Yuen K.Y., Osterhaus A.D., Stohr K. The severe acute respiratory syndrome // N. Engl. J. Med. 2003. V. 349. № 25. P. 2431-2441. https://doi.org/10.1056/ nejmra032498

6. Zaki A.M., van Boheemen S., Bestebroer T.M. et al. Isolation of a novel coronavirus from a man with pneumonia in Saudi Arabia // N. Engl. J. Med. 2012. V. 367. № 19. P. 1814-1820. https://doi.org/10.1056/ nejmoa1211721

7. Al Barrak A.M., Stephens G.M., Hewson R. et al. Recovery from severe novel coronavirus infection // Saudi Med. J. 2012. V. 33. P. 1265-1269. PMID:23232672. 8. Pollack M.P., Pringle C., Madoff L.C., 
Memish Z.A. Latest outbreak news from ProMED-mail: novel coronavirus - Middle East // J. Infect. Dis. 2013. V.17. P. 143-144. https://doi.org/10.1016/j.ijid.2012.12.001

9. Khan G. A novel coronavirus capable of lethal human infections: an emerging picture // Virol. J. 2013. V. 10. P. 66. https://doi.org/10.1186/1743-422X-10-66

10. Bermingham A., Chand M.A., Brown C.S., Aarons E. et al. Severe respiratory illness caused by a novel coronavirus, in a patient transferred to the United Kingdom from the Middle East, September 2012 // Euro Surveill. 2012. V. 17. № 40. P. 20290. PMID:23078800

11. Kossyvakis A., Tao H., Li X., Podka V. et al. Laboratory investigation and phylogenetic analysis of an imported MERS coronavirus. Case in Greece // PLoS One. 2015. V. 10, № 4. e0125809. https://doi.org/10.1371/ journal.pone.0125809

12. Su S., Wong G., Liu Y., Gao G.F. et al. MERS in South Korea and China: a potential outbreak threat? // Lancet. 2015. V. 385. P. 2349-2350. https://doi.org/ 10.1016/S0140-6736(15)60859-5

13. Nishiura H., Endo A., Saitoh M., Kinoshita R. et al. Identifying determinants of heterogeneous transmission dynamics of the MERS outbreak in the Republic of Korea, 2015: a retrospective epidemiological analysis // BMJ Open 2016. V. 6. P. 1-10. https://doi. org/10.1136/bmjopen-2015-009936

14. Shih G., Sun L.H. Specter of possible new virus emerging from central China raises alarms across Asia. Washington Post. URL: https://flipboard. com/@WashPost/specter-of-possible-new-virusemerging-from-central-china-raises-alarms-acrossa/a-LVUQPrl5Qi6rS4m5HImRlg\%3Aa\%3A41916169066088e4a98\%2Fwashingtonpost.com (дата обращения: 09.01.2020).

15. $\mathrm{Hu}$ D.S., Azhar E.I. Madani T.A. et al. The continuing 2019-nCoV epidemic threat of novel coronaviruses in global health - The latest 2019 novel coronavirus outbreak to Wuhan China // Int. J. Infect. Dis. 2020. V. 91. P. 264-266. https://doi.org/10.1016/j. ijid.2020.01.009

16. Lu H., Stratton C.W. Tang Y.W. Outbreak pneumonia of unknown etiology in Wuhan China\& the mystery and the Miracle // J. Medical Virology. 2020. V. 92, № 4. P. 401-402. https://doi.org/10.1002/jmv.25678

17. Zhu N., Zhang D., Wang W. et. al. A Novel coronavirus from patients with pneumonia in China,
2019 // N. Engl. J. Med. 2020. V. 382, № 8. P. 727-733 https://doi.org/10.1056/nejmoa2001017

18. Wu F., Zhao S., Yu B., Chen Y.M. et al. Wuhan seafood market pneumonia virus isolate Wuhan$\mathrm{Hu}-1$, complete genome. NCBI Reference Sequence: NC_045512.2. Journal Unpublished. URL: https://www. ncbi.nlm.nih.gov/nuccore/MN908947 (дата обращения: 15.01.2020).

19. Tang X., Wu C., Li X. et al. On the origin and continuing evolution of SARS-CoV-2. https:// doi.org/10.1093/nsr/nwaa036. URL: https://academic. oup.com/nsr/advance-article/doi/10.1093/nsr/ nwaa036/5775463 (дата обращения: 09.03.2020).

20. Qin A., Hernández J.C. China reports first death from new virus. URL: https://www.wikizero. com/en/2019\%E2\%80\%9320_outbreak_of_novel_ coronavirus_(2019-nCoV) (дата обращения: 12.01.2020).

21. Gan N., Xiong Y., Mackintosh E. China confirms new coronavirus can spread between humans. CNN. URL: https://edition.cnn.com/2020/01/19/asia/ china-coronavirus-spike-intl-hnk/index.html (дата обращения: 20.01.2020).

22. Schnirring L. Virologists weigh in on novel coronavirus in China's outbreak. CIDRAP. (8 January 2020). URL: http://www.cidrap.umn.edu/ news-perspective/2020/01/virologists-weigh-novelcoronavirus-chinas-outbreak (дата обращения: 10.01.2020).

23. Imai N., Dorigatti I., Cori A. et al. Estimating the potential total number of novel Coronavirus cases in Wuhan City, China. Imperial College London. Retrieved 18 January 2020. URL: https://www.imperial.ac.uk/media/imperial-college/ medicine/sph/ide/gida-fellowships/2019-nCoVoutbreak-report-17-01-2020.pdf (дата обращения: 19.01.2020).

24. Li W., Shi Z., Yu M. et al. Bats are natural reservoirs of SARS-like coronaviruses // Science. 2005. V. 310. № 5748. P. 676-679. https://doi.org/10.1126/ science.1118391

25. Guan Y., Zheng B.J., He Y.Q. et al. Isolation and characterization of viruses related to the SARS coronavirus from animals in southern China // Science. 2003. V. 302. P. 276-278. https://doi.org/10.1126/ science.1087139

\section{Об авторах}

Федеральное государственное бюджетное учреждение «48 Центральный научно-исследовательский институт» Министерства обороны Российской Федерации, 141306, г. Сергиев Посад, ул. Октябрьская, д. 11. Сизикова Татьяна Евгеньевна. Научный сотрудник, канд. биол. наук.

Карулина Наталья Васильевна. Младший научный сотрудник.

Петров Александр Анатольевич. Начальник научно-исследовательского отдела, д-р. мед наук.

Лебедев Виталий. Николаевич. Ведущий научный сотрудник, д-р биол. наук, проф.

Борисевич Сергей Владимирович. Начальник Федерального государственного бюджетного учреждения «48 ЦНИИ» Минобороны России, д-р биол. наук, проф., чл.-корр. РАН.

Контактная информация для всехавторов: 48cnii@mil.ru Контактное лицо: Борисевич Сергей Владимирович; 48cnii@mil.ru 


\title{
Novel dangerous emergent coronavirus infection
}

\author{
T.E. Sizikova, N.V. Karulina, A.A. Petrov, V.N. Lebedev, S.V. Borisevich \\ Federal State Budgetary Establishment "48 Central Scientific Research Institute» \\ of the Ministry of the Defence of the Russian Federation, Oktyabrskiy Street 11, \\ Sergiev Posad 141306, Russian Federation
}

\begin{abstract}
The genetic diversity of coronaviruses and their variability are provided by high frequency of recombination of their genomic RNA that assists spontaneous emergence of viruses with new characteristics, which potentially may be agents of novel extremely dangerous and exotic infectious diseases. In December 2019 - January 2020 the novel coronavirus disease, caused by SARS-CoV-2 virus, subsequently named COVID-19 (Corona Virus Disease 2019), was revealed in China. The aim of this work is to analyze the possible mechanism of COVID-19 outbreak and the properties of the possible etiological agent of the disease, SARS-CoV-2 virus. A comparison of zoonotic reservoirs of highly pathogenic human coronaviruses, agents of severe acute respiratory syndrome (SARS), Middle East respiratory syndrome (MERS) and SARS-CoV-2, as well as the clinical signs of the diseases, caused by them, are presented. The possible mechanism of epidemic outbreaks is considered. The chronology of COVID-19 outbreak (later escalated into a pandemic) from the beginning of December to the end of March, taxonomical and molecular-biological characteristics of ethiological agent of disease, SARS-CoV-2 virus, and its place on phylogenetic tree of coronaviruses are presented. The main directions of the struggle with the spread of the infection are considered.
\end{abstract}

Keywords: Middle East Respiratory Syndrome (MERS); coronavirus SARS-CoV-2; coronaviruses; novel coronavirus disease (COVID-19); Severe Acute Respiratory Syndrome (SARS); emergent viral diseases.

For citation: Sizikova T.E., Karulina N.V., Petrov A.A., Lebedev V.N., Borisevich S.V. Novel dangerous emergent coronavirus infection // Journal of NBC Protection Corps. 2020. V. 4. № 1. P. 21-31. https://doi. org/10.35825/2587-5728-2020-4-1-21-31.

\section{Conflict of interest statement}

The authors declare that the research was conducted in the absence of any commercial or financial relationship that could be construed as a potential conflict of interest.

Peer review information

The article has been peer reviewed by two experts in the respective field. Peer reviews are available from the Editorial Board.

\section{References}

See P. 21-31.

Authors

Federal State Budgetary Establishment «48 Central Scientific Research Institute» of the Ministry of the Defence of the Russian Federation. Oktyabrskiy Street 11, Sergiev Posad 141306, Russian Federation.

Tatyana Eugenievna Sizikova. Researcher. Candidate of Biological Sciences.

Natalya Vasilievna Karulina. Junior Researcher.

Alexander Anatolievich Petrov. Head of the Department. Doctor of Medicinal Sciences

Vitaly Nikolayevich Lebedev. Leading Researcher. Doctor of Biological Sciences, Professor.

Sergey Vladimirovich Borisevich. Head of the FSBE «48 Central Scientific Research Institute». Doctor of Biological Sciences, Corresponding Member of RAS.

Contact information for all authors: 48cnii@mil.ru Contact person: Sergey Vladimirovich Borisevich; 48cnii@mil.ru 